\title{
Editorial
}

\section{Food Insecurity and Chronic Diseases: The Editorial}

\author{
Ahmad R Dorosty \\ Department of Community Nutrition, School of Nutritional Sciences and Dietetics, Tehran University of Medical Sciences, Tehran, Iran
}

$\mathrm{F}$ ood Insecurity (FI) defines as the limited or uncertain availability of nutritionally foods adequately or the inability to achieve them in ways which is socially acceptable (1).FI is considered as an international public health issue particularly in developing countries (2). In 1995 the U.S. Department of Agriculture (USDA) reported the prevalence of FI in USA as $11.9 \%$ which increased to $14.6 \%$ in 2008 (3). Its prevalence was reported $5.7 \%$ in Finland, $10 \%$ in Canada (4), 50\% in Malaysia (5) and 70\% in Bolivia (6).

The FI populations are at risk of low intake of fruits and vegetables, lower quality diets and so lower micronutrients intake and iron deficiency anemia (7). Limited available budget in FI subjects, leads to purchase cheaper and high dense calorie foods; which might contribute to obesity, and an increased susceptibility to chronic illnesses including type 2 diabetes, cancer, depression and other medical condition such as acne, dyspepsia and so on (8).

The very first step to reduce the burden of FI is considering understanding ofits effects on health. By now, anumerous studies have aimed to examine the impacts of FI on health outcomes in different age/ gender groups such as children, adults and elder lies. Over the past few years, the paradox of FI and obesity/ overweight, diabetes, cancer and depression has been focused in literatures. Recently the FI have been considered in many other disorders. Literatures show a positive association between FI and acne (9), dyslipidemia (10) and dyspepsia (34\% FI with hunger in patients versus $10 \%$ in counterparts) (9).

There are a set of evidences in Iran (mostly published by the author of this editorial), which show food security is significantly associated with many problems and diseases including low birth weight, short stature in children (as FI increase, the height of children decrease), pre-eclampsia in pregnancy, the type of delivery, obesity/ overweight in women, lower intelligence quotient in children, osteoporosis (33.8\% in food secure versus $66.2 \%$ in FI group), diabetes mellitus, rheumatoid arthritis and premenstrual syndrome (FI without hunger in teenagers with PMS was approximately 2 times more than those without PMS) [Published in Farsi Language]. However, other studies concerning association of FI with other diseases / problems are still needed. On the other hand, finding the prevalence of FI in different Iran provinces to draw a clear picture of FI looks necessary. Therefore, investigators are expected to work on prevalence and diseases associated to FI in their future studies.

\section{Financial disclosure}

The author declare no financial interest.

\section{References}

1. Nord M, Jemison K, Bickel GW. Measuring food security in the United States prevalence of food insecurity and hunger, by state, 1996-1998. Washington, D.C: U.S. Dept. of Agriculture, Economic Research Service 1999.

2. Health Canada. Income-Related Household Food Security in Canada. Canadian Community Health Survey Cycle. Ottawa, Canada, Health Canada. 2.2; 2004.

3. Nord M, Andrews MS, Carlson S. Household food security in the United States, 2008. Washington, DC: U.S. Dept. of Agriculture, Economic Research Service. 2009.

4. Che J, Chen J. Food security in Canadian households. Health Rep 2001; 12(4):11-22.

5. Shariff ZM, Lin KG. Indicators and nutritional outcomes of household food insecurity among a sample of rural Malaysian women. J Nutr 2004; 30:50-5.

6. Melgar-Quinonez HR, Zubieta AC, MkNelly B, Nteziyaremye A, Gerardo MFD, Dunfordy C. Household Food Insecurity and Food Expenditure in Bolivia, Burkina Faso, and the Philippines. J Nutr 2006; 136(5):1431-7. 
7. Dixon LB, Winkleby MA, Radimer KL. Dietary intakes and serum nutrients differ between adults from foodinsufficient and foodsufficient families: Third National Health and Nutrition Examination Survey, 1988-1994. J Nutr 2001; 131(4):1232-46.

8. Lee JS, Frongillo Jr EA. Nutritional and health consequences are associated with food insecurity among U.S. elderly persons. J Nutr 2001; 131(5):1503-9.
9. Vozoris NT, Tarasuk VS. Household food insufficiency is associated with poorer health. J Nutr 2003; 133(1):120-6.

10. Shin JI, Bautista LE, Walsh MC, Malecki KC, Nieto FJ. Food insecurity and dyslipidemia in a representative population-based sample in the US. Prev Med 2015; 77:186-90. 